\title{
Shared-Use Bus Priority Lanes on City Streets: Approaches to Access and Enforcement
}

\author{
Asha Weinstein Agrawal, San José State University \\ Todd Goldman, Port Authority of New York \& New Jersey \\ Nancy Hannaford, Mineta Transportation Institute
}

\begin{abstract}
This paper examines policies and strategies governing the operations of bus lanes in major congested urban centers where the bus lanes do not completely exclude other uses. The two key questions addressed are:

1. What is the scope of the priority use granted to buses? When is bus priority in effect, and what other users may share the lanes during these times?

2. How are the lanes enforced?

To answer these questions, the study developed detailed cases on management strategies in seven cities that currently have shared-use bus priority lanes: Los Angeles, London, New York City, Paris, San Francisco, Seoul, and Sydney. Through the case studies, the paper examines the range of practices in use and highlights innovative ones that may contribute to bus lane success.
\end{abstract}

\section{Introduction}

In recent years, there has been a wave of interest and innovation in strategies to make bus operations more efficient and effective. Amid global interest over fullysegregated transitways such as Bogotá's TransMilenio, the shared-use bus priority lane has often been overlooked. Yet, because it is far more flexible than its higher- 
end cousins, it can be a practical solution in a wide range of contexts, particularly in urban centers where limited street capacities make it impractical to segregate lanes solely for transit use.

This paper examines policies governing the operations of bus priority lanes in congested urban centers. The two key questions addressed in this paper are:

1. What is the scope of the priority use granted to buses? When is bus priority in effect, and what other users may share the lanes during these times?

2. How are the lanes enforced?

In a comprehensive examination of bus priority lanes in seven international cities, the authors documented a range of institutional, design, and operational practices, as well as innovative practices that contribute to bus lane success. (For additional detail beyond that in this paper, see Agrawal, Goldman, and Hannaford 2012.)

\section{Previous Studies on Bus Lanes}

The present study builds upon the existing research by providing a management perspective unusual in the literature, which tends to focus on physical design.

The literature on bus priority treatments dates back to the mid-1950s, though the first comprehensive studies appeared in the 1970s (Levinson et al. 1973; Levinson, Adams, and Hoey 1975; NATO 1976). More recently, there has been a renewed interest in bus lanes, especially as they relate to bus rapid transit (BRT) systems (Levinson et al. 2003; Danaher 2010; Deng and Nelson 2010). Another strand of recent research has looked at proposals for "intermittent" bus lanes that prohibit general traffic only when buses are present (Viegas and Lu 2001; Eichler and Deganzo 2006; Viegas et al. 2007; Currie and Lai 2008). There have also been a few examinations of the policy processes that lead to the development of bus priority systems (Miller and Buckley 2001; Matsumoto 2006).

Comprehensive assessments of the effectiveness of bus lanes have been scarce. City governments' own evaluation studies usually focus on determining whether a recently-installed bus lane should remain in place. Because traffic conditions and street geometry vary so significantly from place to place, and other bus priority treatments and traffic mitigation strategies are often implemented at the same time as bus lanes, it is difficult to draw generalizable conclusions from these studies. Nonetheless, there have been several attempts to distill the impacts of bus lanes and other priority strategies (St. Jacques and Levinson 1997; St. Jacques and 
Levinson 2000; Levinson et al. 2003; Currie 2006; Tsamboulas 2006; Kittelson 2007; McDonnell, Ferreira, and Convery 2006).

\section{Study Methodology}

The primary study method was the development of case studies for Los Angeles, London, New York City, Paris, San Francisco, Seoul, and Sydney. These cities were chosen because they have networks of bus priority lanes running through congested, mixed-use urban districts and policies allowing other vehicles to share the lanes on a limited basis. The cities were also chosen to reflect a diverse range of policy and design choices.

For each case, we reviewed available government reports, academic studies, conference papers, newspaper archives, websites, and local and state laws and regulations, and conducted interviews with local professionals working on bus lane planning, operations, and enforcement. Each case was reviewed by at least one person with expertise on bus lanes in that city. In total, 43 experts either were interviewed by the authors or reviewed a draft and provided comments. In Los Angeles, New York City, Paris, San Francisco, and Sydney, the research team photographed the lanes and observed them in operation.

\section{Case Studies}

The next section discusses the seven case study cities, summarizing notable features about the bus lane system in each. Two following sections summarize key findings from the case studies on the two research questions. A concluding section summarizes the findings.

\section{Overview}

The following section presents a very brief overview of each city's bus lane system, highlighting some notable features. Table 1 presents the date each system was founded and the length of the network at the time the study research was completed.

Table 1. Bus Priority Lane Networks in Case Study Cities

\begin{tabular}{|l|c|c|c|c|c|c|c|}
\hline Characteristic & London & LA & NYC & Paris & SF & Seoul & Sydney \\
\hline Year bus lanes first established & 1968 & 1974 & 1963 & 1964 & 1970 & 1984 & 1992 \\
\hline Miles of bus priority networks* & 177 & 4 & 50 & 118 & 18 & 127 & 14 \\
\hline
\end{tabular}

*Excludes fully-separated transitways.

Sources: See case studies in the appendices of Agrawal, Goldman, and Hannaford 2012. 
London has developed one of the most comprehensive systems of bus priority lanes in the world during the past 40 years. As of 2009, London's bus priority network included 1,200 segments and extended about 177 miles. London has an unusually decentralized approach to bus lane administration, which has been led by the metropolitan government on a network of key arterials, but by local authorities elsewhere. London's bus lane program is also notable for its comprehensive approach to enforcement.

Los Angeles has a small bus priority network of only four miles. The network was first implemented in the 1970s and has been modified but not greatly expanded since. The longest segment of the network functions as an on-street extension of a fully-separated transitway that serves buses and carpools in the median of a freeway. From 2004 to 2007, the city also installed demonstration bus lanes along one mile of a congested stretch of Wilshire Boulevard. The lanes were removed due to some local opposition, but the city plans to reinstate them as part of a longer bus priority project in the corridor.

New York City has been developing a bus lane network for nearly five decades, during which time it has reinvented its system several times with new branding, design, and enforcement strategies. The network extends about 50 miles, mostly in short segments distributed around the city. Recently, New York has started to introduce comprehensively-planned, longer-distance bus priority lanes. New York is just beginning to implement camera-based enforcement of bus lanes on a limited basis.

Paris began developing a network of curbside bus lanes in the 1960s. Today, the system extends 118 miles. Over the past decade, bus lanes have been widened, and low granite curbs have been installed on about one-third of the bus lane network to physically segregate the lanes from general traffic (see Figure 1). These are not exclusive bus lanes because taxis, bicycles, and other vehicles may also use them, but they have a greater degree of separation than can be achieved by paint alone.

San Francisco has 14 miles of bus priority lanes. To improve enforcement, the city has recently experimented with new relationships with the police and a pilot camera enforcement program. To a greater extent than any of the other case study cities, San Francisco's bus priority lanes are offset from the curb to allow other vehicles to access the curb lane throughout the day (see Figure 2). 


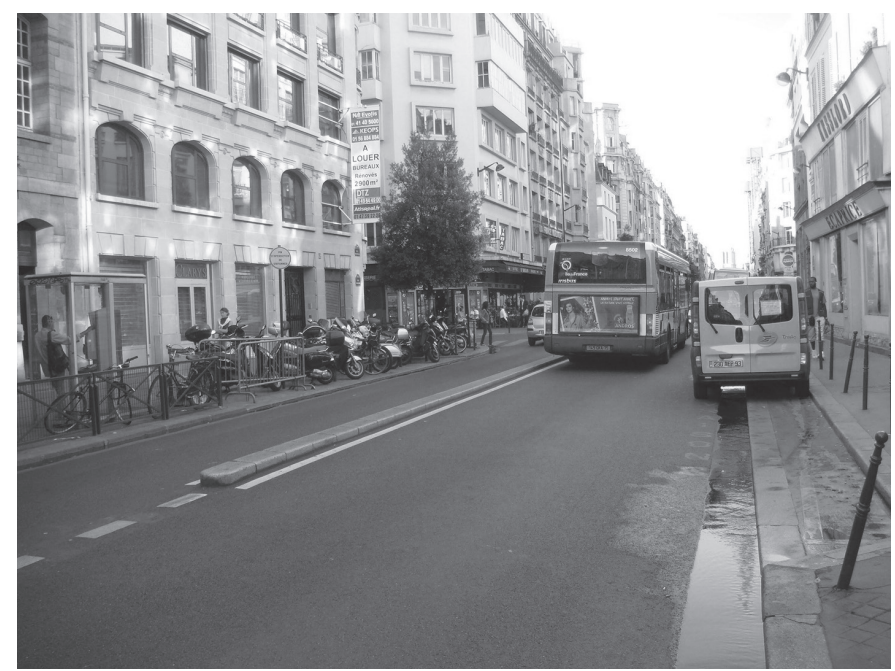

Photo by Asha W. Agrawal

Figure 1. Raised curb delineating bus lane and marked delivery parking spot within a bus lane (Paris)

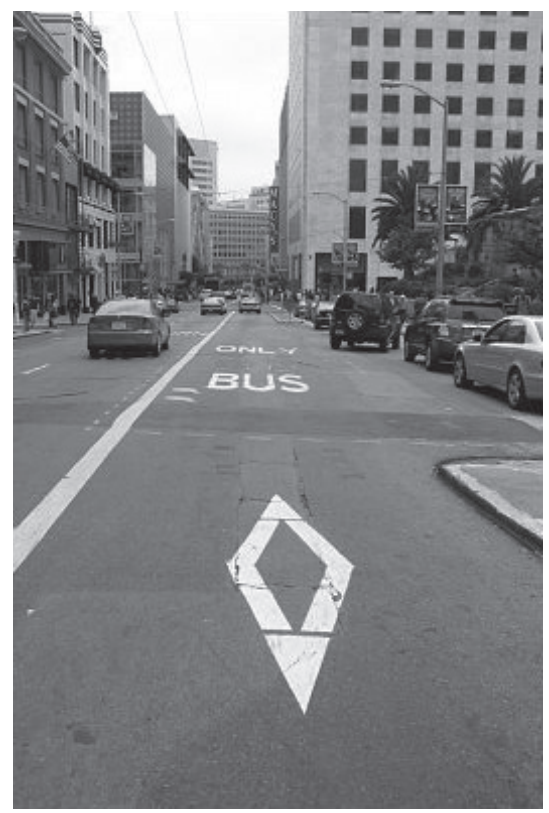

Photo by Jennifer Donlon

Figure 2. Parking bay to the right side of a San Francisco bus lane 
Seoul developed a comprehensive system of curbside bus lanes beginning in the 1980s. Since 2004, it has upgraded many of its bus lane corridors to operate in the median, adapting its surface transit system to keep pace with the city's rapid population and economic growth. However, its median bus lanes retain some shared use, since other vehicles may use the lanes to make left turns in some locations.

Sydney is the smallest of the cities examined here and has the newest bus priority lane network. It is unique for its reliance on fully-automated camera-based bus lane enforcement. Its bus priority lanes also have a range of different levels of access granted to other vehicles, including "transitways" intended for the exclusive use of buses (but not located in Inner Sydney), and "bus lanes" that facilitate buses but also allow taxis and turning vehicles as well.

\section{Access Policies}

Through access policies, bus priority lanes can strike a context-sensitive balance between the goal of unimpeded transit operations and the needs of other street space users. Use of this shared space can be allocated by time of day, or specific classes of vehicles can be allowed limited use of the lane.

In most cities, it proved surprisingly challenging to determine these access policies with precision. Municipal or other legal codes provide only a starting point for understanding these policies, since cities often have power to tailor rules on a location-specific basis. Street signage and pavement markings sometimes provided simplified representations of more complex regulations. Also, in some cases, police appeared to have their own informal criteria for administering bus lane rules that did not exactly match the legal codes or posted rules.

\section{Hours of Operation}

The hours of operation for bus lanes varied greatly, both between and within cities (see Table 2). The most common approach was for bus priority lane restrictions to be in force only during weekday peak periods, usually for two to four hours at a time. Outside of these hours, the lanes were used for general traffic, parking, or commercial deliveries. Among the cities examined here, peak-hour operations were prevalent in London, Los Angeles, New York, and Sydney, full-time lanes were more common in Paris and Seoul, and San Francisco had good numbers of both part-time and full-time lanes. Paris was the only city examined with no part-time bus lanes. 
Table 2. Bus Lane Hours of Operation (Approximate Percent of Total Lane Miles)

\begin{tabular}{|l|c|c|c|c|c|c|c|}
\hline Hours of Operation & London & LA & NYC & Paris & SF & Seoul & Sydney \\
\hline 24 hours, 7 days per week & $29 \%$ & & $<2 \%$ & $100 \%$ & $66 \%$ & $44 \%$ & $12 \%$ \\
\hline Daytime hours, typically weekdays & $25 \%$ & & $40 \%$ & & $11 \%$ & $32 \%$ & $18 \%$ \\
\hline Peak periods only & $46 \%$ & $100 \%$ & $58 \%$ & & $23 \%$ & $24 \%$ & $70 \%$ \\
\hline
\end{tabular}

Standardizing hours of operation helps drivers learn more easily when they can and cannot use the lanes. However, allowing the hours to be tailored to local conditions allows better coordination with congestion and bus volumes, both of which can vary greatly from street to street within a city.

\section{Access to Bus Lanes for Specific Vehicle Types}

Cities set bus priority lane access rules to keep buses moving efficiently, while making allowances for users who either must use the lane (i.e., vehicles turning into a property) or users whose travel the city wishes to facilitate (i.e., taxis or bicycles). This shared access uses the bus lane capacity more fully and allows safe operations (e.g., by allowing vehicles to approach right turns from within the bus lane rather than crossing through it).

In every case study city, certain users were permitted in the bus lanes under any circumstance, while other specified users were permitted into the bus lanes only for limited, designated purposes. The rules often differed in terms of the users and uses for which traveling and stopping or parking in the lanes was permitted. Table 3 provides an overview of users permitted in bus lanes in the cities studied.

The case study cities were divided on whether to allow bicycles to use bus lanes. London, Los Angeles, Paris, and Sydney permitted bicycles to travel in most bus lanes, except where particular locations posed safety concerns. In Paris, this was a deliberate policy to improve bicycle access. By contrast, New York, San Francisco, and Seoul did not allow bicycles to use bus lanes. Bike access to bus lanes is a matter of considerable debate in the street engineering community. Some see the two modes as fundamentally compatible because over longer distances, both travel at similar speeds. Others see them as incompatible because bicycles move at a constant speed while buses start and stop. 
Table 3. Non-Bus Users Permitted in Bus Lanes

\begin{tabular}{|c|c|c|c|c|c|c|c|}
\hline Type of User & London & LA & NYC & Paris & SF & Seoul & Sydney \\
\hline \multicolumn{8}{|l|}{ Users permitted at all times } \\
\hline Bicycle & $\bullet$ & $\bullet$ & & $\bullet$ & & & $\bullet$ \\
\hline Motorcycle/moped & $\bullet$ & & & & & & $\bullet$ \\
\hline Taxi & $\bullet$ & $\bullet$ & & $\bullet$ & $\bullet$ & & $\bullet$ \\
\hline Municipal or utility vehicle on business & $\bullet$ & $\bullet$ & & & & $\bullet$ & $\bullet$ \\
\hline Disabled-placard holder & & & & & & $\bullet$ & \\
\hline Carpool & & & & & & $6+$ & \\
\hline \multicolumn{8}{|c|}{ Users permitted to travel in bus lanes under certain conditions } \\
\hline $\begin{array}{l}\text { Any vehicle turning at nearest } \\
\text { intersection (no more than } 1 \text { block) }\end{array}$ & $\bullet$ & $\bullet$ & $\bullet$ & & $\bullet$ & $\bullet$ & $\bullet$ \\
\hline $\begin{array}{l}\text { Any vehicle entering/exiting drive- } \\
\text { way or curb parking along block }\end{array}$ & $\bullet$ & $\bullet$ & $\bullet$ & $\bullet$ & $\bullet$ & $\bullet$ & $\bullet$ \\
\hline \multicolumn{8}{|l|}{ Users permitted to stop in bus lanes } \\
\hline Taxi loading/unloading & $\bullet$ & $\bullet$ & $\bullet$ & $\bullet$ & $\bullet$ & $\bullet$ & $\bullet$ \\
\hline Any vehicle loading/unloading & & & $\bullet$ & & & & \\
\hline \multicolumn{8}{|l|}{$\begin{array}{l}\text { Disabled-placard holder loading/ } \\
\text { unloading }\end{array}$} \\
\hline $\begin{array}{l}\text { Delivery vehicle, for loading/ } \\
\text { unloading, as posted }\end{array}$ & $\bullet$ & & $\bullet$ & - & $\bullet$ & & \\
\hline
\end{tabular}

- = Yes, for at least some lanes in the system. Empty cell indicates either "no" or "don't know." Sources: See case studies in the appendices of Agrawal, Goldman, and Hannaford 2012.

Use of bus lanes by motorcyclists and other motorized two-wheel vehicles is also a contentious issue in several cities. Until recently, only Sydney permitted motorcyclists to travel in bus lanes as regular policy. Interviewees from two cities mentioned that the police do not prioritize ticketing motorcyclists in bus lanes, even though they are illegal users. In London, Transport for London (TfL) conducted two trials to see if motorcyclists could be integrated into bus lanes safely and with meaningful time-savings benefits, and in 2012, the Agency legalized motorcycle use for most of its bus network.

All of the case study cities except New York and Seoul permitted taxis to travel in bus lanes. This policy is often based on the premise that taxis are a critical mode supporting residents who choose to live car-free or to use cars minimally. Similarly, 
most of the cities allowed bus lane use by jitneys, or privately-owned multi-passenger vehicles that serve a regular route but are not contracted service providers for a publicly-owned or managed transit system.

Four of the seven case study cities explicitly permitted some travel in bus lanes by government-owned vehicles and/or utility vehicles such as refuse collection vehicles, city-owned cars used for official city business, and mail delivery trucks. All of the cities allowed emergency vehicles to use the bus lanes, although some cities specified that these vehicles must be traveling to an actual emergency. Paris allowed doctors traveling to visit a patient to use the lanes.

\section{Access to Bus Lanes for Designated Purposes}

All the case study cities allow a private vehicle to travel in a bus priority lane for some maximum distance (up to one block) to access a driveway located in that block. And in all the cities except Paris, any vehicle could normally drive in a bus lane for a short distance in order to make a turn at the nearest approaching intersection. For example, in San Francisco, a vehicle may travel up to one block in a bus lane for the purposes of turning, while in New York, no maximum distance is specified, as long as the vehicle makes its first legal right turn. Finally, in New York City, Seoul, and Sydney, any vehicle may temporarily travel in a bus lane to avoid an obstacle.

All of the case cities permitted taxis to stop in bus lanes to load or unload passengers, and several cities granted the same right to private-hire vehicles like charter buses or limousines. London permitted vehicles bearing "disabled" placards to stop in a bus lane to load or unload passengers, and New York, uniquely, granted the same privilege to any private vehicle.

Three of the cities allowed delivery vehicles to stop in bus lanes for loading and unloading, at least during certain hours or in certain locations. Paris had perhaps the most sophisticated such system, with special loading spots that permit buses to pass stopped delivery vehicles (see Figure 2). These designated loading areas extend part way into the sidewalk and part way into the bus lane. Delivery vehicles could use these spots in off-peak hours, which are indicated on street signs. New York, for its part, limited some of its curbside bus lanes to peak-hour operations in order to permit commercial deliveries during mid-day hours. 


\section{Enforcement}

Effective enforcement is a perennial challenge to the effectiveness of bus lanes. If drivers come to expect that there is a high probability they will get caught for driving or parking in a bus lane, they will generally heed the rules. But if they come to expect a low risk of getting caught, some will begin to venture into the lane, preventing the lane from providing legal users with the intended free-flow travel.

\section{Laws and Penalties}

The legal systems of the case study cities and counties differ, but a key distinction is the treatment of a bus lane violation as an infraction versus as an administrative violation. The distinction is important because although the penalties for infractions can be more severe, they are far more difficult to administer and, if not matters of public safety, they are often unenforced.

In most of the case study cities, driving in a bus lane was considered to be a moving violation. Moving violations, or violations of laws concerning the operation of vehicles, are typically considered infractions or misdemeanors. In these cases, charges are usually filed by a sworn law enforcement officer directly against the operator of a vehicle, and the driver is subject to a hearing in court. In addition to fines, such offenses can result in penalties against the driver's license to operate a vehicle, or even in jail time.

In contrast, the laws concerning the parking of vehicles (including parking illegally in a bus lane) are generally considered administrative violations of the law. Parking tickets are often administrative notices that can be issued by agents who are not fully-sworn police officers. These tickets do not require identification of the individual who parked the vehicle illegally and are instead issued to the vehicle's registered owner. The tickets result in an automatic fine without the need for a court hearing, although the recipient of a parking ticket can typically request a hearing before a judge.

In some cities, there have been efforts to enable citations for moving violations in bus lanes to be handled as administrative violations so that they may be issued by automated cameras or traffic control agents who are not police officers, and to reduce the evidentiary and procedural burden of enforcing them. London, Paris, San Francisco, and Seoul had laws that enable enforcement by traffic agents or, in some cases, by camera. In Los Angeles and New York, bus lane moving violations remained infractions. New York had authorized camera-based enforcement on some new bus lanes, and in these cases somewhat lower civil fines were issued. 
Sydney used a hybrid approach. Bus lane moving violations were enforced either by police patrols or else by the state transportation agency using automated cameras. The violations were handled administratively (without court proceedings) but could result in points being added to a vehicle owner's license. To avoid these points, the onus was on the vehicle owner to prove that somebody else was operating the vehicle.

\section{Patrol-Based Enforcement}

Historically, it has been difficult for the police to sustain bus lane enforcement efforts amid the many other issues pressing for their attention. Cities have tried a variety of methods to maintain a police focus on bus lane enforcement. In London, the municipal transportation agency contracted with the police department to provide services related to safety, maintenance of traffic flow, enforcement of bus lanes, and other objectives, and a dedicated command unit was established to carry out the agreement. In San Francisco, the police established a dedicated unit with a focus on bus lane enforcement and other traffic issues. This unit operates under the supervision of the transportation agency.

A common alternative to continuous enforcement of bus lanes is "sweep" or "blitz" style enforcement, where intensive enforcement activities are conducted periodically for brief periods. Because of their high resource requirements, these efforts cannot be sustained for long. They can help raise public awareness of the law, but have little residual effect if some visible enforcement effort is not maintained between sweeps. Paris and Los Angeles have used such brief but intensive enforcement campaigns when first introducing bus lanes.

All of the case study cities relied primarily on civilian enforcement agents to issue violations for parking in a bus lane, usually as part of units that enforce parking regulations more generally. In most, these were employees of the city's transportation agency, a separate parking agency, or some other administrative unit. Police agencies in London, New York, and Paris had dedicated units for parking enforcement consisting of non-sworn (civilian) employees. New York and Paris also empowered certain transit agency employees to issue parking tickets for bus lane violations. Additional parking enforcement powers were held by some sub-municipal entities, including London's boroughs and Seoul's Gu (administrative districts).

\section{Camera-Based Enforcement}

Automated, camera-based enforcement of bus lanes provides an attractive alternative to patrol-based enforcement strategies. There are no gaps in enforcement 
as long as the equipment is working properly, and the high detection rate provides a strong deterrent. Also, while cameras do not eliminate the need to commit personnel resources to the overall enforcement effort, the approach largely shifts personnel time to a more manageable back-office operation.

However, camera-based enforcement has a number of political, legal, and administrative challenges, and it has only been implemented widely in a few cities. In places where driving in bus lanes is treated as an infraction, it can be difficult for camerabased systems to meet evidentiary standards (e.g. proof of the driver's identity). Bus lane enforcement cameras also face the same public concerns that make speed and red light cameras unpopular: the potential for privacy violations, questions about reliability, perceptions that the cameras are implemented only to generate revenue, and concerns that drivers trying to avoid fines will drive unsafely.

Stationary cameras have been implemented most extensively in London and have also been adopted in New York, Paris, Seoul, and Sydney. London and Paris both experimented with bus-mounted cameras, but neither found the technology to be practical. New York, San Francisco, and Seoul also had bus-mounted camera trials planned or underway. Some cities experimented with portable cameras that can be deployed to problem areas as needed: "smart car patrols" in London and mobile camera units in Seoul. Of the case study cities, only Los Angeles had not implemented any camera-based bus lane enforcement.

The technologies used for bus lane cameras varied from city to city and were evolving rapidly. In most of the cities, agents reviewed raw footage or electronicallyselected excerpts to identify cases where violations have occurred and should be prosecuted. Sydney relied on computer processing of high-resolution photos taken at intervals along the bus lanes and issued violation notices automatically to vehicles detected by consecutive cameras.

Table 4 summarizes camera-based enforcement in the cities studied.

\section{Passive Enforcement}

One passive enforcement strategy that some cities had adopted is "offset" or "interior" bus lane alignments, which reserve space for a general travel or stopping lane along the curb. These have long been used in San Francisco and were becoming widely used in London, New York, Paris, and Sydney. This approach preserves curb access for parking, loading, and turns, while reducing the degree to which these activities conflict with buses. These types of lanes are often said to be "self-enforcing" because their location away from the curb makes them much less prone to 
Table 4. Camera-Based Enforcement

\begin{tabular}{|c|c|c|c|c|c|c|c|}
\hline Feature & London & LA & NYC & Paris & SF & Seoul & Sydney \\
\hline Camera-based enforcement employed & $\bullet$ & & $\bullet$ & $\bullet$ & $P$ & $\bullet$ & $\bullet$ \\
\hline \multicolumn{8}{|l|}{ Type of laws enforced by camera } \\
\hline Moving violations & $\bullet$ & & $\bullet$ & • & & $\bullet$ & $\bullet$ \\
\hline Parking/stopping violations & $\bullet$ & & & $\bullet$ & $\bullet$ & $\bullet$ & $\bullet$ \\
\hline \multicolumn{8}{|l|}{ Administrating agency } \\
\hline Police department & • & & & $\bullet$ & & & \\
\hline $\begin{array}{l}\text { Transit operator/other municipal } \\
\text { agency }\end{array}$ & & & $\bullet$ & & $\bullet$ & • & $\bullet$ \\
\hline \multicolumn{8}{|l|}{ Camera placement } \\
\hline On-board buses & & & $P$ & $P$ & $P$ & $P$ & \\
\hline Stationary (along street) & $\bullet$ & & $\bullet$ & $\bullet$ & & $\bullet$ & $\bullet$ \\
\hline Mobile units, patrol vehicles & $\bullet$ & & $\mathrm{P}$ & & & $\bullet$ & \\
\hline \multicolumn{8}{|l|}{ Analysis of images to verify violations } \\
\hline Automated & & & & & & & $\bullet$ \\
\hline Manual & $\bullet$ & & • & • & • & • & \\
\hline
\end{tabular}

$P=$ Pilot testing

Sources: See case studies in the appendices of Agrawal, Goldman, and Hannaford 2012.

being blocked by stopped vehicles. A second passive enforcement strategy is Paris's use of low curbs separating bus lanes from general traffic. These discourage general traffic from entering the bus lane, without preventing all non-bus users outright.

\section{Conclusion}

This survey examined the policies used to manage bus priority lanes in cities with a broad range of political cultures and institutional environments. Overall, it found a wide array of different strategies in use, rather than convergence on a single universal set of strategies.

In general, bus priority lanes seek to improve bus speeds while addressing the access and mobility needs of other transportation system users. This balance can be achieved in multiple ways, such as allowing other vehicles to access the bus lane under defined conditions, scheduling different uses for the lane during different times of day, and positioning the bus lane to change the mix of users affected by the bus lane's presence. In general, nearly every city studied allowed all vehicles to 
use curbside bus priority lanes to make right turns (left turns in the UK and Australia) and to access driveways on a given block. Taxis were universally allowed to use the lanes to pick up and discharge passengers. Several cities authorized bicycles and taxis to drive in a bus lane as well. Other exemptions were more unusual. As for hours of bus priority, while bus lanes operated around the clock in a few of the cities, in most they only operated during peak hours of public transit use.

With respect to bus lane enforcement, cities are typically constrained by their political and legal systems to a limited number of enforcement options available. Enforcement of laws concerning the operation of motor vehicles is usually a police responsibility, and granting police powers to a civilian transportation agency is not possible. States and cities had dealt with this challenge in various ways. Some had laws classifying bus lane violations as civil infractions that can be enforced by civilian agents and/or by automated cameras. Others had developed contractual or supervisory relationships between police and transportation agencies to ensure that there were personnel directly responsible for bus lane enforcement. An additional approach was to use design strategies like physical barriers or offset bus lanes that reduce the need for enforcement.

\section{Acknowledgements}

The authors thank the Mineta Transportation Institute at San José State University for funding this research. In addition, we offer deep thanks to the many people who contributed to this study, including Alejandro Blei, Harika Boga, Jennifer Donlon, Dennis Freeman, Jeff Gerlach, Cameron Gordon, Roland Jezek, Camille Kamga, Seon Joo Kim, Herbert S. Levinson, Robert Paaswell, Jose Pillich, Mark Seaman, Arjun Thyagarajan, and the many professionals who volunteered their time as interviewees and reviewers of draft cases. All errors or omissions are the responsibility of the author.

\section{References}

Agrawal, A. W., T. Goldman, and N. Hannaford. 2012. Shared-Use Bus Priority Lanes on City Streets: Case Studies in Design and Management. San Jose: Mineta Transportation Institute.

Currie, G. 2006. Bus rapid transit in Australasia: Performance, lessons learned and futures. Journal of Public Transportation 9(3): 1-22. 
Currie, G., and H. Lai. 2008. Intermittent and dynamic transit lanes: Melbourne, Australia, Experience. Transportation Research Record 2072: 49-56.

Danaher, A. R. 2010. Bus and Rail Transit Preferential Treatments in Mixed Traffic, TCRP Synthesis 83. Washington, DC: Transit Cooperative Research Program, Transportation Research Board.

Deng, T., and J. D. Nelson. 2010. Recent developments in bus rapid transit: A review of the literature. Transport Reviews 31(1): 69-96.

Eichler, M., and C. F. Daganzo. 2006. Bus lanes with intermittent priority: Strategy formulae and an evaluation. Transportation Research B 40(9): 731-744.

Kittelson \& Associates, Inc. 2007. Bus Rapid Transit Practitioner's Guide, TCRP Report 118. Washington, DC: Transit Cooperative Research Program, Transportation Research Board.

Levinson, H. S., C. L. Adams, and W. F. Hoey. 1975. Bus Use of Highways: Planning and Design Guidelines, NCHRP Research Report 155. Washington, DC: Highway Research Board, National Research Council.

Levinson, H. S., et al. 1973. Bus Use of Highways: State of the Art, NCHRP Report 143. Washington, DC: Highway Research Board, National Research Council.

Levinson, H., et al. 2003. Bus Rapid Transit: Volume 1: Case Studies in Bus Rapid Transit, TCRP Research Report 90. Washington, DC: Transit Cooperative Research Program, Transportation Research Board.

Levinson, H., et al. 2003. Bus Rapid Transit: Volume 2: Implementation Guidelines, TCRP Report 90. Washington, DC: Transit Cooperative Research Program, Transportation Research Board.

Matsumoto, N. 2006. Analysis of policy processes to introduce bus rapid transit systems in Asian cities from the perspective of lesson-drawing: Cases of Jakarta, Seoul, and Beijing. Presented at the Better Air Quality Workshop, 2006, Yogyakarta, Indonesia. http://www.iges.or.jp/en/ue/pdf/activity03/ BAQ_IGES_Ma.pdf. Accessed July 25, 2011.

McDonnell, S., S. Ferreira, and F. Convery. 2006. Impact of bus priority attributes on catchment area residents in Dublin, Ireland. Journal of Public Transportation 9(3): 137-162.

Miller, M., and S. Buckley. 2001. Bus rapid transit institutional issues: The route from research to experience. Transportation Research Record 1760: 34-41. 
NATO Committee on the Challenges of Modern Society. 1976. Bus Priority Systems, CCMS Report 45. London: Transport and Road Research Laboratory, Department of the Environment.

St. Jacques, K. R., and H. S. Levinson. 1997. Operational Analysis of Bus Lanes on Arterials, TCRP Report 26. Washington, DC: Transit Cooperative Research Program, Transportation Research Board.

St. Jacques, K. R., and H. S. Levinson. 2000. Operational Analysis of Bus Lanes on Arterials: Application and Refinement, TCRP Research Results Digest. 38. Washington, DC: Transit Cooperative Research Program, Transportation Research Board.

Tsamboulas, D. 2006. Ex-ante evaluation of exclusive bus lanes implementation. Journal of Public Transportation 9(3): 201-217.

Viegas, J., and B. Lu. 2001. Widening the scope for bus priority with intermittent bus lanes. Transportation Planning and Technology 24(2): 87-110.

Viegas, J. M., et al. 2007. Intermittent bus lane system: Demonstration in Lisbon, Portugal. Presented at 86th Annual Meeting of the Transportation Research Board, Washington, DC.

\section{About the Authors}

Asha Weinstein AgraWAL (asha.weinstein.agrawal@sjsu.edu) is the Director of the MTI National Transportation Finance Center and also an associate professor and chair of the Department of Urban and Regional Planning at San José State University. Her research and teaching interests in transportation policy and planning include transportation finance, pedestrian planning, urban street design, and transportation history. She holds a Ph.D. from the University of California at Berkeley in city and regional planning.

TODD Goldman (tgoldman0@gmail.com) is Manager, Regional Transportation Planning at the Port Authority of New York and New Jersey. Previously, he worked as Associate Director for New Initiatives at the Region 2 University Transportation Research Center at the City College of New York. He holds a Ph.D. from the University of California at Berkeley in city and regional planning.

NANCY HANNAFORD (nancy.hannaford@earthlink.net) comes to urban and transportation planning research from a professional background spanning more than 
20 years in computer engineering and operating system development. She presently divides her time between working as an editor and researcher for planning projects and privately consulting as a process efficiency expert in agribusiness. She has a B.A. in computer science from the University of California, Berkeley. 